\title{
Method of VIL Calculation for X-band Polarimetric Radar and Potential of VIL for Nowcasting of Localized Severe Rainfall - Case Study of the Zoshigaya Downpour, 5 August 2008 -
}

\author{
Kohin Hirano and Masayuki Maki \\ National Research Institute for Earth Science and Disaster Prevention, Tsukuba, Japan
}

\begin{abstract}
This paper discusses the availability of the vertically integrated liquid (VIL) water content product from 3-cm wavelength polarimetric radar in precipitation detection and estimation. Based on a case of localized severe rainfall around Zoshigaya, Tokyo, Japan on 5 August 2008, VIL values are compared with radar derived rain intensity and surface rain-gauge data. VIL is calculated by three methods: (1) using only the horizontal reflectivity $(Z),(2)$ using only specific differential phase $\left(K_{\mathrm{DP}}\right)$, and (3) using both $Z$ and $K_{\mathrm{DP}}$. Two integral height scales are tested: a height near the melting layer $(5 \mathrm{~km})$ and a height over the echo top $(15 \mathrm{~km})$. The composite method of $Z$ and $K_{\mathrm{DP}}$ proved to be the best approach for calculating VIL. VIL values were consistent with gauge measurements: the maximum normalized cross-correlation coefficients at all three observation sites (Edogawa Elementary School, Daiichi Junior High School, and Toshima Branch) exceed 0.9, and detection by VIL has a 5-10 min lead time than gauge measurements.
\end{abstract}

\section{Introduction}

Urban floods caused by localized severe rainfall, such as those that occurred along the Toga River (Kobe) and at Zoshigaya (Toshima district, Tokyo) in 2008, have become a matter of wide concern in Japan. Such severe rainfall has a small horizontal scale, random occurrence, and develops without being triggered by an organized cloud system, thereby making it difficult to forecast such event using existing forecasting systems. Consequently, it is important to develop precise detection and early warning system for localized severe rainfall.

Quantitative precipitation nowcasting using radar measurements is expected to address this need. Boudevillain et al. (2006) developed a precipitation forecasting model (RadVil) to predict very short-term rainfall from vertically integrated liquid (VIL) water content derived from C-band operational radar, yielding performance equivalent or better than that of operational forecasting models. VIL, which is a radar-derived measure of the total amount of water above a point, measured in $\left(\mathrm{kg} \mathrm{m}^{-2}\right)$ (Rinehart 2004), is a convenient parameter that includes vertical information on total water but does not need to consider the microphysical processes of rainfall. In the past 40 years, extensive research has been conducted on the use of VIL, as measured by conventional radar, in hail detection and quantitative precipitation forecasting (Greene and Clark 1972; Amburn and Wolf 1997; Thielen et al. 2000). In conventional radar, VIL is generally estimated using the $Z-M$ (radar reflectivity - liquid water content) relationship. This gives rise to accuracy problems because of errors affecting the measured reflectivity itself, such as variations in drop size distribution (DSD), attenuation, contamination by ice particles, and hardware calibration errors (Brandes et al. 1999). However, these limitations of VIL may be overcome by using polarimetric radar observations, such as the specific differential phase $\left(K_{\mathrm{DP}}\right.$; Park et al. 2005; Bringi and Chandrasekar 2001).

Against the above background, this paper provides a case

Corresponding author: Kohin Hirano, National Research Institute for Earth Science and Disaster Prevention, 3-1, Tennodai, Tsukuba 305-0006, Japan. E-mail: hirano@bosai.go.jp. C2010, the Meteorological Society of Japan. study of VIL calculation for X-band (3-cm wavelength) polarimetric radar of a severe rainfall event that occurred near Zoshigaya, Tokyo, on 5 August 2008, to investigate the potential of using VIL in nowcasting of localized severe rainfall. Section 2 describes the data and method for deriving VIL from polarimetric radar observations. Section 3 presents the calculation result while Section 4 gives a conclusion and a short discussion.

\section{Conditions and methodology}

\subsection{Case study and MP-X}

During the late morning on 5 August 2008, the Zoshigaya area of Tokyo was struck by a sudden "Pulse" -type convective rainfall event. It began to rain at about 1140 (Japan Standard Time, JST; hereafter, all times are JST), and by 1205 the rainfall intensity had grown to over $100 \mathrm{~mm}$ per hour. This severe rainfall, known as the Zoshigaya "guerrilla" downpour, resulted in five sewer workers being swept away by a flash flood while constructing sewer lines. Because of its sudden development and limited range, the rainfall was neither explicitly detected by operational radar nor by surface observations (Automated Meteorological Data Acquisition System, AMeDAS) of the Japan Meteorological Agency (JMA). According to sounding data recorded at Tateno at 0900 and 2100 (Supplement 1), the atmosphere was relatively stable during the day and had negligible vertical wind shear. The MSM (MesoScale Model) of JMA did not forecast the associated rain cloud. Although Kato and Maki (2009) found that X-band polarimetric radar was able to detect this sudden rainfall, the time delay of the rain peak activity locally exceeded $5 \mathrm{~min}$. This paper focuses on VIL values of the Zoshigaya downpour, over the period from 1130 to 1330 .

MP-X (Multi-Parameter radar at X-band wavelength) is the research polarimetric radar of the National Research Institute for Earth Science and Disaster Prevention (NIED) at Ebina, Kanagawa, Japan, about $50 \mathrm{~km}$ southwest of Tokyo. The locations of MP-X and Zoshigaya are shown in Fig. 1. MP-X has been in operation since 2003 for the purpose of improving the detection and prediction of severe weather (Maki et al. 2005a). MP-X performs a volume scan that consists of a series of full-circle PPI scans at elevation tilts of $0.7^{\circ}, 1.1^{\circ}, 1.6^{\circ}, 2.1^{\circ}, 2.6^{\circ}, 3.2^{\circ}, 3.8^{\circ}$, $4.6^{\circ}, 5.6^{\circ}, 6.9^{\circ}, 8.4^{\circ}$, and $10.3^{\circ}$, within $5 \mathrm{~min}$. The $3-\mathrm{dB}$ horizontal beamwidth and radar range are $1.3^{\circ}$ and $80 \mathrm{~km}$, respectively. VIL in the Zoshigaya downpour case was extracted using MP-X volumetric reflectivity $(Z)$ and $K_{\mathrm{DP}}$.

\subsection{VIL estimation method}

Three methods were assessed in deriving VIL from MP-X measurements. The first is the traditional method using the $Z-M$ relationship, while the second estimates VIL from the $K_{\mathrm{DP}}-M$ relationship. The expressions for the traditional method and for the $K_{\mathrm{DP}}$ method are shown in Eqs. (1) and (2), respectively, in which the coefficients for each equation are from Maki et al. (2005b).

$$
\begin{aligned}
& V I L_{\mathrm{z}}=\int_{0}^{\mathrm{h}} M(Z) d h=\int_{0}^{\mathrm{h}} 0.00393 Z^{0.550} d h, \\
& V I L_{\mathrm{KDP}}=\int_{0}^{\mathrm{h}} M\left(K_{\mathrm{DP}}\right) d h=\int_{0}^{\mathrm{h}} 0.991 K_{\mathrm{DP}}^{0.713} d h .
\end{aligned}
$$


Here, $h$ indicates the vertical range over which VIL is calculated. The units for $Z$ and $K_{\mathrm{DP}}$ are $\left(\mathrm{mm}^{6} \mathrm{~m}^{-3}\right)$ and $\left(\mathrm{deg} \mathrm{km} \mathrm{km}^{-1}\right.$ ), respectively. In both equations, it is assumed that all precipitation particles are in the form of liquid water throughout the layer, despite the fact that ice particles may exist and thereby contribute to the measurement error of VIL, particularly when using $Z$. Therefore, the quantitative error is not discussed in this paper. Additionally, from distribution of $Z$ and $K_{\mathrm{DP}}$ data (see Supplement 2 ) it is known that there is no hail signature during the objective period and no signature of the melting layer is found in the analyzed convective precipitation cells.

$K_{\mathrm{DP}}$ measured by polarimetric radar is less sensitive to DSD variation and the presence of hail in contrast to $Z$ (Zrnic and Ryzhkov 1996; Maki et al. 2005b), but may encounter problems in the case of weak rainfall. To overcome these limitations, a composite approach is employed in the third method. The composite method is based on Eq. (2), although Eq. (1) is applied in the case that $K_{\mathrm{DP}} \leq 0.3 \mathrm{deg} \mathrm{km}{ }^{-1}$ or $Z \leq 35 \mathrm{dBZ}$ in order to deal with weak rainfall, as suggested by Park et al. (2005).

Another important point is correction for reflectivity. Because $\mathrm{X}$-band radar reflectivity suffers strong attenuation when propagating through severe rainfall, MP-X reflectivity was corrected (before VIL calculation) using the attenuation correction algorithm proposed by Kim et al. (2008). The corrected reflectivity $(Z)$ and $K_{\mathrm{DP}}$ were produced in the Constant Altitude Plan Position Indicator (CAPPI) format with a grid resolution of $500 \times 500 \mathrm{~m}$ in the horizontal and $250 \mathrm{~m}$ in the vertical. Integration was then performed.

\section{Results}

\subsection{Influence of integral height}

VIL value varies with the integral height. To examine how VIL changed when integral height was varied, VIL at $1 \mathrm{~km}$ to $15 \mathrm{~km}$, the echo-top level of the analyzed convective precipitation cell detected by MP-X, is investigated. Supplement 3 shows parts of the results. VIL value increases linearly with height at lower

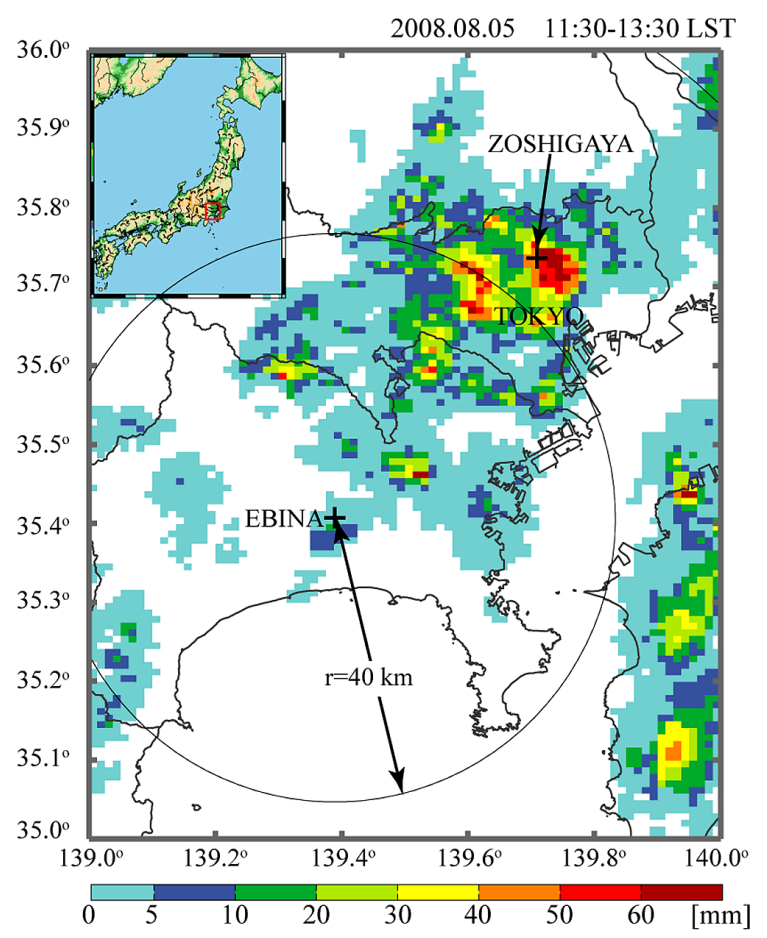

Fig. 1. Map showing the locations of MP-X (EBINA) and Zoshigaya. The color scale shows the precipitation amount from 1130 to 1330 LST on 5 August 2008 (from Radar-AMeDAS, JMA). (a) VIL

2008.08.05 12:00 12:05 LST

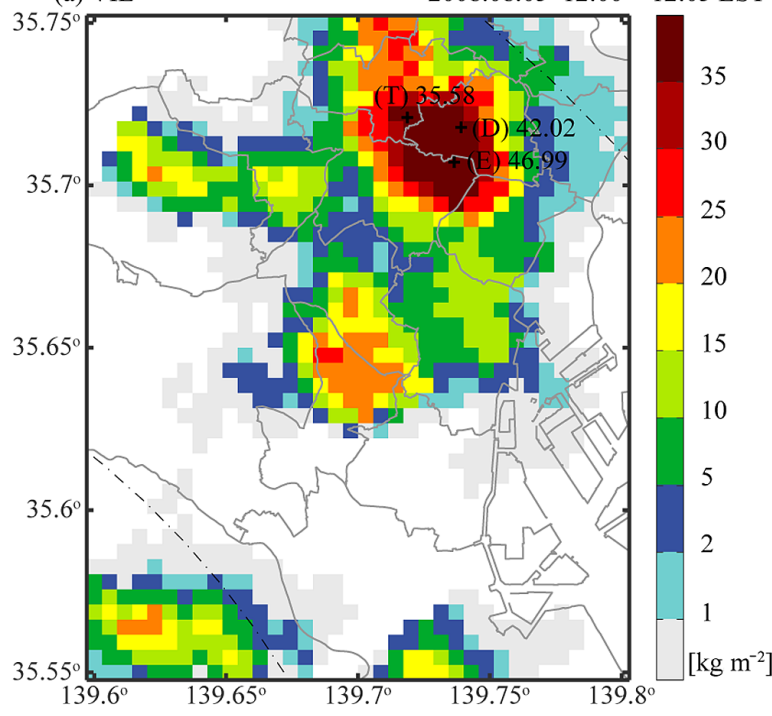

(b) $\mathrm{VIL}_{2}$

2008.08.05 12:00 12:05 LST

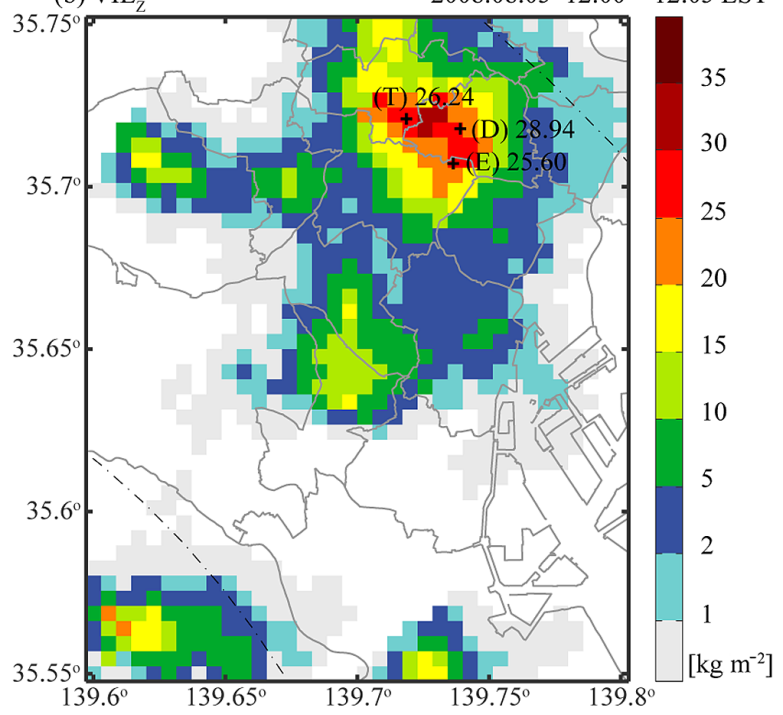

(c) $\mathrm{VIL}_{\mathrm{KDP}}$ 2008.08.05 12:00 12:05 LST

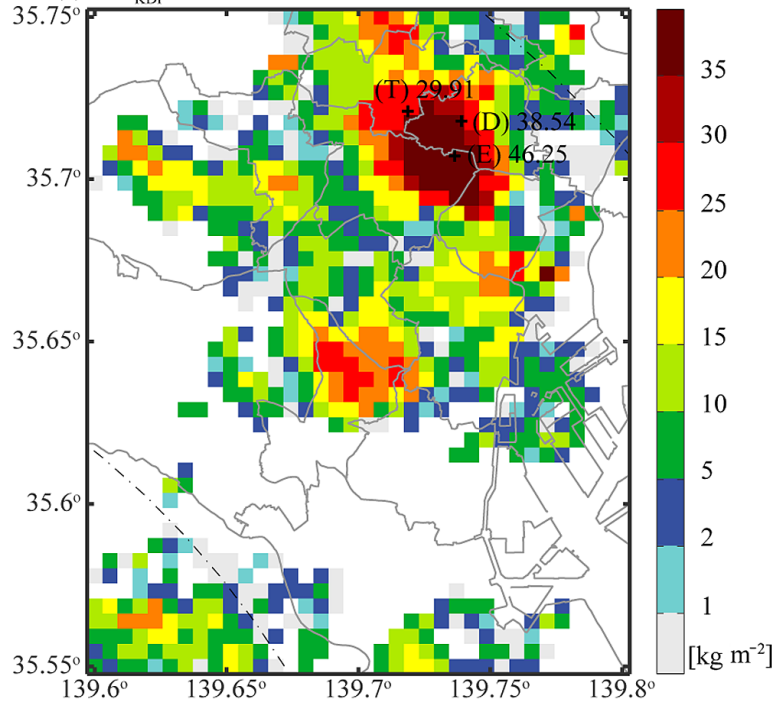

Fig. 2. Comparison of VIL obtained by three different methods at 1200 LST, 5 August 2008. (a) composite method, (b) traditional method, and (c) $K_{\mathrm{DP}}$ method. E, D, and T denote Edogawa Elementary School, Daiichi Junior High School, and Toshima Branch, respectively. 
layers $(\sim 6 \mathrm{~km})$, and such linear proportion can be kept higher $(8 \mathrm{~km})$ when $15 \mathrm{~km}$ VIL is very small $\left(<10 \mathrm{~kg} \mathrm{~m}^{-2}\right)$.

Detailed analysis results at two integral heights are given below. One is a height matching that of the summer melting layer altitude $(5 \mathrm{~km})$ and the other is the echo top height $(15 \mathrm{~km})$.

\subsection{Influence of calculation method}

Figure 2 provides an example of the distribution of VIL calculated using the three methods described above for the radar volume scan beginning at 1200 on 5 August 2008. The integral height is $15 \mathrm{~km}$ from the ground surface to the highest echo top. $\mathrm{E}, \mathrm{D}$, and $\mathrm{T}$ in the figure represent the locations of surface raingauge stations at Edogawa Elementary School, Daiichi Junior High School, and the Toshima Branch of the Bureau of Sewerage, Tokyo Metropolitan Government, respectively. The number that follows each letter in the figure indicates the VIL value of the relevant grid point. VIL calculated by $K_{\mathrm{DP}}\left(\mathrm{VIL}_{\mathrm{KDP}}\right.$, Fig. $\left.2 \mathrm{c}\right)$ generally shows higher values than those calculated by $Z\left(\mathrm{VIL}_{\mathrm{Z}}\right.$, Fig. $2 b$ ), but fails to represent very low VIL levels (gray shading) and shows a patchy distribution. Values of VIL calculated using $Z$ only are about $40 \%$ lower, on average, than those obtained using $K_{\mathrm{DP}}$ only. There is no significant difference in this underestimate in the cases of integration over 5 and $15 \mathrm{~km}$.

Figure 3 shows an intercomparison of $15 \mathrm{~km}$ VIL (true VIL) calculated by three methods for grids (36 grids) around the three rain-gauge stations during the objective time. The $\mathrm{x}$-axis represents the results calculated by composite method, while the y-axis shows results derived from $Z$ (a) or $K_{\mathrm{DP}}$ (b) alone. Although the
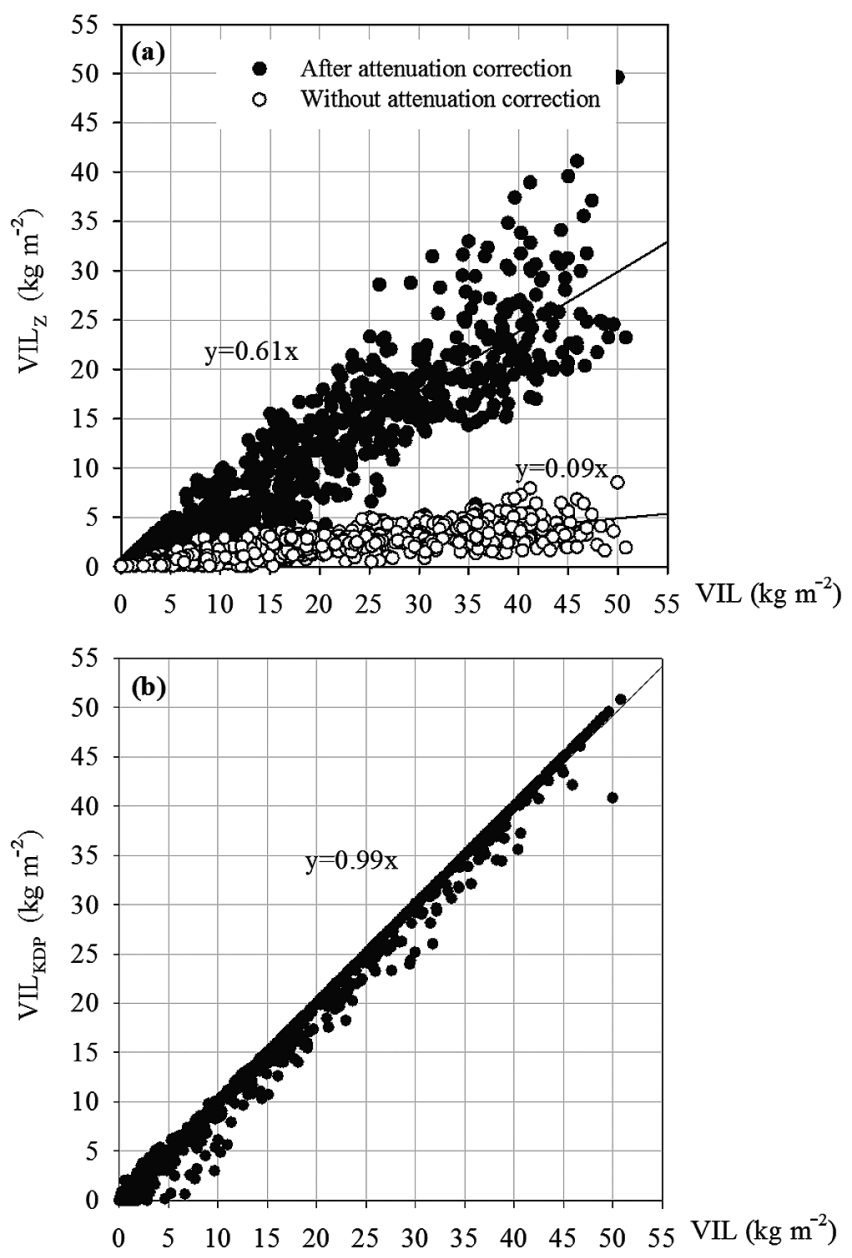

Fig. 3. Intercomparison of $15 \mathrm{~km}$ VIL calculated by three methods. (a) Traditional method $\left(\mathrm{VIL}_{\mathrm{Z}}\right)$ versus the composite method (VIL), and (b) $K_{\mathrm{DP}}$ method $\left(\mathrm{VIL}_{\mathrm{KDP}}\right)$ versus the composite method. attenuation correction resulted in a significant increase in the sensitivity of $Z$-derived VIL, it shows lower values than VIL derived from $K_{\mathrm{DP}}$. It is clear from Fig. $3 \mathrm{~b}$ that VIL obtained from $K_{\mathrm{DP}}$ is adopted by composite method for most of the VIL calculations, although this method oscillates between using $K_{\mathrm{DP}}$ and $Z$ in the case that VIL is low (especially when less than $10 \mathrm{~kg} \mathrm{~m}^{-2}$ ).

\subsection{Comparison of VIL and gauge measurements}

Figure $4 \mathrm{a}-\mathrm{c}$ compares time series of surface gauge measurements (GAUGE), MP-X-derived rain intensity (RAIN), and VILs for the three observation sites mentioned above. RAIN is estimated using the lowest-elevation scan $\left(0.7^{\circ}\right)$. Note that gauge measurements are collected every $10 \mathrm{~min}$, but MP-X products have a 5-min interval. The three observation sites are within $1.1 \mathrm{~km}$ of each other, yet they show contrasting rainfall patterns. The rainfall event at $E$ shows a single peak that appeared $\sim 40$ min after the start of rainfall. At D and T, rainfall tapered off at 1230 but increased in intensity after a further $10 \mathrm{~min}$. The value of RAIN is in close agreement with the gauge measurements, which indirectly proves the accuracy of estimating water contents from $K_{\text {DP. }}$. Compared to RAIN, VILs record earlier signs of rainfall, giving the appearance that VIL curves are shifted slightly to the left in the figure. At most time points, $\mathrm{VIL}_{\mathrm{z}} 5 \mathrm{~km}$ shows a lower value than VIL $_{\mathrm{KDP}} 5 \mathrm{~km}$. VIL $\mathrm{VI}_{\mathrm{Z}} 5 \mathrm{~km}$ underestimates the peak and

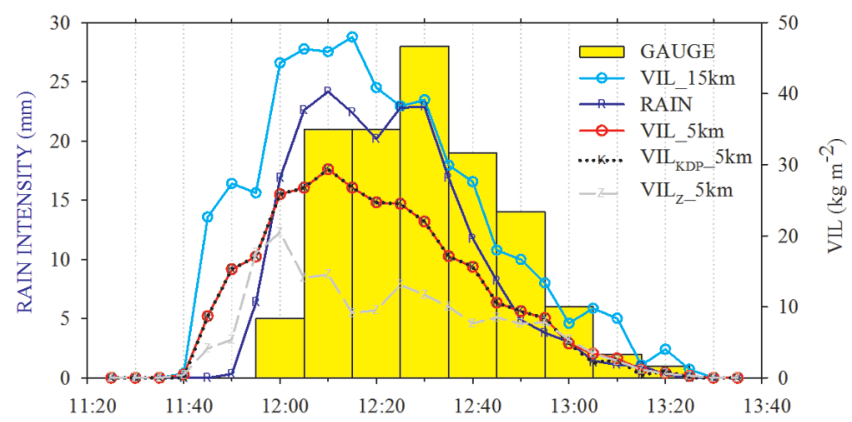

(a) Edogawa Elementary School

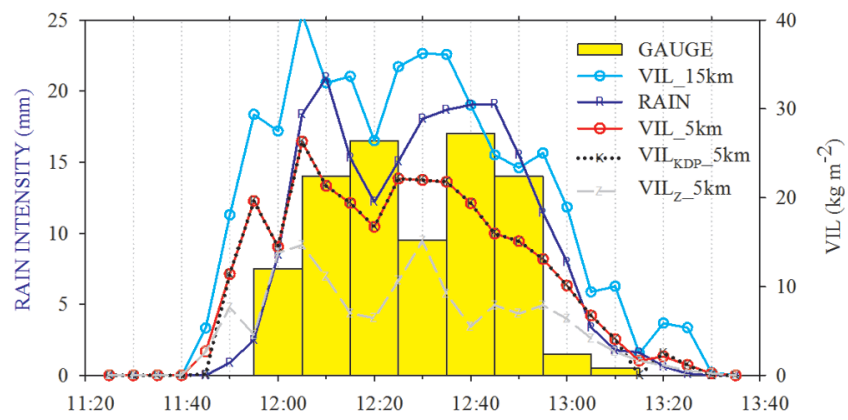

(b) Daiichi Junior High School

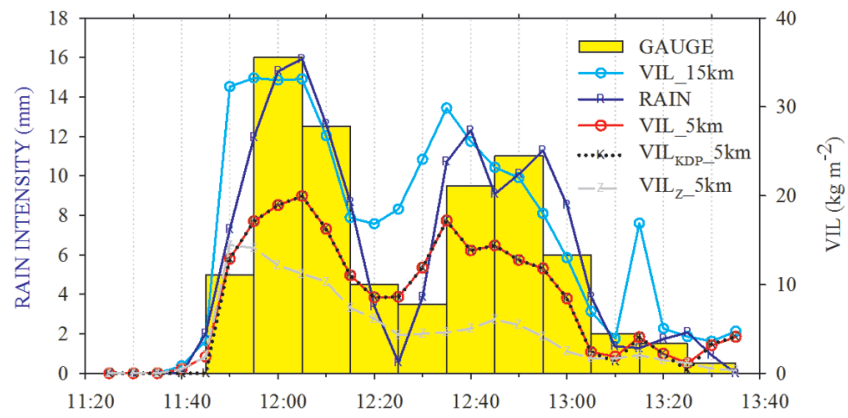

(c) Toshima Branch

Fig. 4. Time series comparison of gauge measurements (GAUGE), MP-Xderived rain intensity (RAIN), and VILs for the Zoshigaya downpour. 
Table 1. Correlation and maximum cross-correlation coefficients of rain intensity (RAIN) and VIL against gauge measurements. Number in brackets shows the lead time in unit of min.

\begin{tabular}{lclllc}
\hline & RAIN & VIL_5km & VIL_15km & VIL $_{\text {Z_ }} 15 \mathrm{~km}$ & VIL $_{\text {KDP_ }} 15 \mathrm{~km}$ \\
\hline Site E & 0.87 & $0.97(10)$ & $0.97(10)$ & $0.97(10)$ & $0.97(10)$ \\
Site D & 0.91 & $0.94(10)$ & $0.94(10)$ & $0.93(10)$ & $0.91(10)$ \\
Site T & 0.97 & $0.96(0)$ & $0.93(10)$ & $0.93(0)$ & $0.99(10)$ \\
\hline
\end{tabular}

average by approximately $30 \%$ and $40 \%$, respectively, compared with VIL $\mathrm{KDP}_{-} 5 \mathrm{~km}$. VIL $\mathrm{KDP}_{-} 5 \mathrm{~km}$ detects the initial upward trend of the VIL curve 5 min later than does VIL $_{z_{-}} 5 \mathrm{~km}$. VIL within the lowest $5 \mathrm{~km}$ (VIL $5 \mathrm{~km}$ ) is approximately $55 \%$ of VIL $15 \mathrm{~km}$; however, the two curves show similar temporal variations. This finding indicates that true VIL does not give an earlier sign of rainfall than does $5 \mathrm{~km}$ VIL.

Table 1 lists the correlation and normalized maximum crosscorrelation coefficients of rain intensity (RAIN) and VILs (VIL_5km, VIL_15km, VIL ${ }_{Z_{-}} 15 \mathrm{~km}$, and $\mathrm{VIL}_{\mathrm{KDP}}+15 \mathrm{~km}$ ) against gauge measurements. Although the absolute values of VIL $5 \mathrm{~km}$ and VIL_15km are different, the relationship between VIL_ $5 \mathrm{~km}$ and gauge measurements at all three points is equivalent to that between VIL_15km and gauge measurements (not shown). All of the correlation coefficients for RAIN and the normalized maximum cross-correlation coefficients for VIL exceed 0.85 . At observation points $E$ and $D$, the normalized maximum cross-correlation coefficient is obtained by increasing the lead time to $10 \mathrm{~min}$; at $\mathrm{T}$, it is obtained for a lead time of $10 \mathrm{~min}$ for VIL $15 \mathrm{~km}$ (and VIL $_{\text {KDP__ }} 15 \mathrm{~km}$ ) only.

\section{Conclusion and discussion}

This paper studies the influence of calculation method on VIL estimates and compares VIL, as derived from X-band multiparameter polarimetric radar, with gauge measurements. The following interesting results were obtained.

The use of $K_{\mathrm{DP}}$ gives good results for most times and places, but tends to omit very weak rainfall, while $Z$ tends to underestimate VIL. Hence, the combination of $Z$ and $K_{\mathrm{DP}}$ is the best approach for estimating VIL from radar measurements. Consistent relationships were found between VIL and gauge measurements. We obtained a high (cross-) correlation coefficient between VIL and gauge measurements, and detection by VIL has a slightly earlier lead time than gauge measurements. The lead time of VIL reflects the time taken for raindrops to reach the ground surface, as VIL involves the information on precipitable water in the upper atmosphere.

In addition, VIL beneath $5 \mathrm{~km}$ shows very similar temporal variations to those of VIL up to the echo top. In the case of the Zoshigaya downpour, three precipitation cores were generated within $1 \mathrm{hr}$ at $3-4 \mathrm{~km}$ above ground (personal communication); this height is the general case for convective precipitation cores in Japan. This may be a factor in explaining the similar temporal variations of the two VILs. Another factor is the negligible vertical wind shear on the day of interest. Additional studies are required in this regard. Nevertheless, this finding indicates that integrated water content to a certain height may yield efficacy equivalent to that of true VIL.

The Ministry of Land, Infrastructure, Transport and Tourism (MLIT, Japan) has started a project to install X-band polarimetric radars in three major metropolitan areas and major cities in Japan for the forecasting and warning of severe rainfall events. Our findings suggest the potential of VIL as an indicator of localized severe rainfall in nowcast/forecast systems. In addition, it can contribute to the efficient use of X-band polarimetric radar networks.

\section{Acknowledgments}

Surface rain-gauge data were provided by the Tokyo Metropolitan Government. We thank A. Kato and D.-S. Kim for helpful comments and advice.

\section{Supplements}

Supplement 1 shows the sounding data at 0900 and 2100 LST 5 August 2008

Supplement 2 gives the distribution of $Z$ and $K_{\mathrm{DP}}$ at $1200 \mathrm{LST}$ 5 August 2008.

Supplement 3 shows the relationship between VIL and integral height.

\section{References}

Amburn, S. A., and P. W. Wolf, 1997: VILdensity as a hail indicator. Wea. Forecasting, 12, 473-478.

Boudevillain, B., H. Andrieu, and N. Chaumerliac, 2006: Evaluation of RadVil, a radar based very short-term rainfall forecasting model. J. Hydrometeor., 7, 178-189.

Brandes, E. A., J. Vivekanandan, and J. W. Wilson, 1999: A comparison of radar reflectivity estimates of rainfall from collocated radars. J. Atmos. Oceanic Technol., 16, 1264-1272.

Bringi, V. N., and V. Chandrasekar, 2001: Polarimetric Doppler weather radar, Cambridge, 534-540.

Greene, D. R., and R. A. Clark, 1972: Vertically integrated liquid water - A new analysis tool. Mon. Wea. Rev., 100, 548-552.

Kato, A., and M. Maki, 2009: Localized heavy rainfall near Zoshigaya, Tokyo, Japan on 5 August 2008 observed by $\mathrm{X}$-band polarimetric radar - preliminary analysis-. SOLA, $\mathbf{5}$, 89-92.

Kim, D.-S., M. Maki, and D.-I. Lee, 2008: Correction of X-band radar reflectivity and differential reflectivity for rain attenuation using differential phase. Atmos. Res., 90, 1-9.

Maki, M., V. N. Bringi, and H. Uyeda, 2005a: Semioperational rainfall observations with X-band multi- parameter radar. Atmos. Sci. Lett., 6, 12-18.

Maki, M., S.-G. Park, and V. N. Bringi, 2005b: Effect of natural variations in rain drop size distributions on rain rate estimators of $3 \mathrm{~cm}$ wavelength polarimetric radar. J. Meteor. Soc. Japan, 83, 871-893.

Park, S.-G., M. Maki, K. Iwanami, V. N. Bringi, and V. Chandrasekar, 2005: Correction of radar reflectivity and differential reflectivity for rain attenuation at X-band. Part II: Evaluation and application. J. Atmos. Oceanic Technol., 22, 1633-1655.

Rinehart, R. E., 2004: Radar for Meteorologists, Rinehart publications, $450 \mathrm{pp}$.

Thielen, J., B. Boudevillain, and H. Andrieu, 2000: A radar data based short-term rainfall prediction model for urban areas A simulation using meso-scale meteorological modeling. $J$. Hydrol., 239, 97-114.

Zrnic, D. S., and A. V. Ryzhkov, 1996: Advantages of rain measurements using specific differential phase. J. Atmos. Oceanic Technol., 13, 454-464.

Manuscript received 8 March 2010, accepted 22 June 2010

SOLA: http://www.jstage.jst.go.jp/browse/solal 